\title{
Obtenção e caracterização de espumas de cimento de fosfato de cálcio: avaliação dos métodos de emulsão e gelcasting
}

\section{(Fabrication and characterization of calcium phosphate cement foams: evaluation of emulsion and gelcasting methods)}

\author{
E. de Sousa ${ }^{1}$, M. Motisuke ${ }^{1}$, C. A. Bertran ${ }^{2}$ \\ ${ }^{1}$ Instituto de Ciência e Tecnologia - DCT, Universidade Federal de S. Paulo - UNIFESP, \\ S. José dos Campos, SP 12231-280 \\ ${ }^{2}$ Instituto de Química - IQ, Universidade Estadual de Campinas - UNICAMP, C.P. 6154, Campinas, SP 13083-970 \\ eliandra.sousa@unifesp.br,motisuke@unifesp.br,bertran@iqm.unicamp.br
}

\begin{abstract}
Resumo
Em Engenharia Tecidual, a fabricação de scaffolds capazes de guiar o crescimento, a organização e a diferenciação de células no processo de formação de novos tecidos apresenta grande relevância. Várias são as técnicas de processamento para a fabricação desta classe de material: réplica de esponjas poliméricas, incorporação de material orgânico ao pó cerâmico, gelcasting, emulsão, entre outras. Na fabricação de scaffolds focados na terapia de tecidos ósseos, os cimentos de fosfato de cálcio (CFC) apresentam grande destaque, pois além de reabsorvíveis, apresentam morfologia e composição química semelhante à fase mineral óssea. Este trabalho tem como objetivo a obtenção de espumas de CFC por meio de duas rotas de processamento, emulsão e gelcasting. As espumas foram caracterizadas quanto suas propriedades físicas e mecânicas e as fases cristalinas formadas após a cura do cimento foram determinadas por difração de raios X. As amostras obtidas por ambos os métodos apresentaram porosidade entre 58-62\% e microestrutura constituída de poros aproximadamente esféricos $\left(\mathrm{d}_{50}=50-100 \mu \mathrm{m}\right)$. A resistência mecânica das amostras variou entre 5,5-1,5 MPa. As fases cristalinas encontradas foram monetita $\left(\mathrm{CaHPO}_{4}\right)$ e brushita $\left(\mathrm{CaHPO}_{4} 2 \mathrm{H}_{2} \mathrm{O}\right)$.

Palavras-chave: cimento de fosfato de cálcio, emulsão, gelcasting, scaffolds.
\end{abstract}

Abstract

In Tissue Engineering, the need for scaffolds which are capable of guiding the organization, differentiation and growth of cells leading to the formation of new tissues is highly relevant. For the development of new scaffolds focused on bone tissue therapy, calcium phosphate cements $(C P C)$ have great potential, because besides their resorbability, they present morphology and chemical composition similar to the bone mineral phase. Moreover, there are several processing techniques to produce ceramic scaffolds: polymeric sponge replication, incorporation of organic material into the ceramic powder, gelcasting, emulsion, among others. The aim of this work was to obtain CPCs foams by using two processing routes, emulsion and gelcasting. The foams were characterized by their physical and mechanical properties and the crystalline phases formed after the setting reaction of cement were determined by X-ray diffraction. The samples obtained by both methods presented porosity between 58-62\% and the microstructure consists of nearly spherical pores $\left(d_{50}=50-100 \mu \mathrm{m}\right)$. The mechanical strength of the samples ranged from 5.5 to $1.5 \mathrm{MPa}$. The crystalline phases found were monetite $\left(\mathrm{CaHPO}_{4}\right)$ and brushite $\left(\mathrm{CaHPO} \mathrm{H}_{4} \mathrm{H}_{2} \mathrm{O}\right)$.

Keywords: calcium phosphate cement, emulsion, gelcasting, scaffolds.

\section{INTRODUÇ̃̃O}

Os cimentos de fosfato de cálcio (CFC) são formados pela combinação de um ou mais sais de fosfatos de cálcio (FCa) que ao serem misturados com uma fase líquida formam uma pasta que endurece espontaneamente a temperatura ambiente ou corpórea como resultado da precipitação de um ou vários $\mathrm{FCa}[1,2]$. Estes materiais representam uma alternativa às cerâmicas cristalinas de $\mathrm{FCa}$ obtidas por sinterização em altas temperaturas $\left(>1000{ }^{\circ} \mathrm{C}\right)$ como a hidroxiapatita e o fosfato tricálcico. OsCFCsapresentam excelentes biocompatibilidade, bioatividade, osteocondutividade e são reabsorvíveis. No entanto, existem alguns aspectos a serem melhorados, questões cruciais como o controle da taxa de reabsorção, a valorização do potencial osteogênico, e o cumprimento das exigências e necessidades clínicas do cirurgião [3]. Nos últimos anos, novas estratégias que exploram as propriedades intrínsecas dos CFCs tem sido investigadas, como a possibilidade de empregá-los na fabricação de scaffolds para o cultivo celular. Estudos biológicos e práticas clínicas mostram que em adição à composição química do material, a estrutura de poros tridimensional é necessária para permitir adesão, proliferação e diferenciação celular e promover o fluxo de nutrientes e remoção de produtos metabólicos [4].

Vários são os métodos de processamento para a obtenção de espumas cerâmicas: método da esponja 
polimérica, incorporação de materiais orgânicos ao pó cerâmico, geração de bolhas dentro da suspensão, controle nas condições de sinterização com o objetivo de alcançar uma parcial densificação, gelcasting, emulsão, entre outros [5-8]. Neste trabalho duas rotas de processamento foram usadas para a geração de espumas de cimento de fosfato de cálcio (ECFC), emulsão e gelcasting. O método de emulsão é um método simples e consiste na mistura de dois líquidos imiscíveis em que um deles está disperso em outro na forma de gotículas, geralmente estabilizadas por um emulsificante, que se localiza na interface entre as fases líquidas, reduzindo a tensão interfacial. As emulsões podem ser classificadas conforme sua fase contínua: água em óleo (w/o) apresenta gotículas de água dispersas na fase óleo contínua, enquanto óleo em água $(\mathrm{o} / \mathrm{w})$ consiste em gotículas de óleo dispersas em água [9]. O processo de gelcasting desenvolvido pelo Oak Ridge National Laboratory $[10,11]$ foi inicialmente aplicado a produção de materiais de alta densidade. O método baseiase na introdução de monômeros orgânicos a uma suspensão aquosa do pó cerâmico, que por meio da polimerização in situ produzem um reticulado tri-dimensional que consolida a matriz cerâmica. Para a produção de materiais cerâmicos porosos, esta técnica foi associada à aeração de uma suspensão contendo um agente espumante. Em ambos os métodos avaliados, a gelificação do sistema ocorre por meio da cura do CFC, a qual se dá pela hidratação das partículas de fosfato de cálcio. Nesse processo há a dissolução de íons, a nucleação e a precipitação das fases hidratadas que formam fortes ligações com as partículas vizinhas e, desta maneira, promovem o endurecimento do sistema [12].

Diante deste contexto, este trabalho tem como objetivo estudar a viabilidade da produção de espumas de CFC por emulsão e gelcasting. As espumas de CFC foram caracterizadas quanto suas propriedades físicas, mecânicas e morfológicas.

\section{MATERIAIS E MÉTODOS}

As espumas de cimento de fosfato de cálcio foram preparadas com base no sistema $\beta-\mathrm{TCP} / \mathrm{H}_{3} \mathrm{PO}_{4}$. O cimento foi obtido por meio da mistura $(\mathrm{L} / \mathrm{P}=0,80 \mathrm{~mL} / \mathrm{g})$ do pó de $\beta$-TCP $\left(\mathrm{Ca}_{3}\left(\mathrm{PO}_{4}\right)_{2}\right.$, Sigma Aldrich, $\mathrm{d}_{50}=7 \mu \mathrm{m}, 10 \%<\mathrm{d}<$ $90 \%=0,987<\mathrm{d}<15,934)$ e uma solução aquosa de $3 \mathrm{~mol} / \mathrm{L}$ de ácido ortofosfórico (Vetec, $\mathrm{H}_{3} \mathrm{PO}_{4}$ ) e $0,08 \mathrm{~mol} / \mathrm{L}$ de ácido cítrico (Vetec, $\mathrm{C}_{6} \mathrm{H}_{8} \mathrm{O}_{7}$ ). A principal função do ácido cítrico é envolver as partículas de TCP dando-lhes cargas altamente negativas, gerando repulsão e criando uma defloculação. Conseqüentemente, a molhabilidade das partículas e a fluidez da pasta do cimento são aumentadas. Por causa deste processo, o ácido cítrico interfere na cinética da reação de cura tornando-a mais lenta [13].

No método da emulsão (E-ME), o hexano (Synth) foi adicionado à pasta de cimento, que continha duas gotas de surfactante (Renex 40, Oxiteno), em uma relação volumevolume de 1:1. Em seguida, este sistema foi mantido sob agitação mecânica por 2 min. No método de gelcasting (E-MG), foi adicionado à fase líquida do cimento $12 \% \mathrm{em}$ massa de surfactante (Renex 40, Oxiteno). Em seguida, esta mistura foi submetida à agitação por 2 min até a formação de uma espuma que foi misturada cuidadosamente com o pó cerâmico. A Tabela I resume as condições de obtenção de cada amostra bem como a sua nomenclatura.

Em ambos os casos, após a homogeneização do sistema, a pasta resultante foi vertida em moldes cilíndricos de Teflon ${ }^{\circledR}$ (12 $\mathrm{mm}$ de diâmetro e $6 \mathrm{~mm}$ de altura) e deixados secar em temperatura ambiente por $24 \mathrm{~h} \mathrm{e}$, em seguida, desmoldados.

A densidade geométrica $\left(\rho_{\text {geo }}\right)$ foi medida a partir das dimensões e massa dos corpos de prova. A fração de vazios das espumas foi determinada pela porosidade $\varepsilon$, expressa por $\left[1-\left(\rho_{\mathrm{geo}} / \rho_{\mathrm{t}}\right)\right]$, considerando-se a densidade $\rho_{\mathrm{t}}=2,92 \mathrm{~g} / \mathrm{cm}^{3}$. Os resultados obtidos foram analisados estatisticamente por meio do teste ANOVA. A morfologia e a microestrutura das espumas de cimento de fosfato de cálcio foram analisadas por microscopia eletrônica de varredura (Jeol 5900LV). As amostras foram dispostas sobre uma fita de carbono e recobertas com uma fina camada de ouro (Bal-Tec MCS 010). As fases cristalinas formadas após a cura do cimento foram determinadas por difração de raios X (Shimadzu XRD 7000, $2 \theta=10-40^{\circ}, 30 \mathrm{~mA}$ e $40 \mathrm{kV}$ ). A resistência mecânica das ECFC foi determinada por meio de ensaio de compressão uniaxial que foi realizado a temperatura ambiente em uma máquina de ensaios universal (Instron 5500R) com velocidade de carregamento $0,5 \mathrm{~mm} / \mathrm{min}$ e célula de carga de $2 \mathrm{kN}$. Para cada grupo estudado, foram testados pelo menos 10 corpos de prova Os resultados obtidos foram também analisados estatisticamente por meio do teste ANOVA.

Como material de controle, o CFC sem aditivos foi preparado e suas propriedades foram comparadas com as das espumas.

\section{RESULTADOS E DISCUSSÃO}

A Fig. 1 apresenta os difratogramas de raios $\mathrm{X}$ das espumas, do CFC e de pó do $\beta$-TCP. A cura do cimento

Tabela I - Condições de fabricação das espumas e nomenclatura das amostras.

[Table I - Foams fabrication conditions and samples nomenclature.]

\begin{tabular}{cccc}
\hline Amostra & Método & $\mathrm{L} / \mathrm{P}(\mathrm{mL} / \mathrm{g})$ & Condições \\
\hline CFC & Convencional & & $\mathrm{L} / \mathrm{P}=0,80 \mathrm{~mL} / \mathrm{g}$ \\
E-ME & Emulsão & 0,80 & Adição de hexano em relação 1:1 (v/v) \\
E-MG & Gelcasting & & Adição de $12 \%$ em massa de surfactante \\
\hline
\end{tabular}


resultou, em todos os casos, em uma mistura de monetita $\left(\mathrm{CaHPO}_{4}, \mathrm{DCPA}\right.$, JCPDS 9-0080) e brushita $\left(\mathrm{CaHPO}_{4}\right.$ $2 \mathrm{H}_{2} \mathrm{O}$, DCPD, JCPDS 09-0077). De fato, analisando as micrografias da superfície de fratura das amostras (Fig. 2) verifica-se a presença de agulhas que são as responsáveis pela resistência mecânica do material (monetita e brushita) e de partículas de fosfato de cálcio ( $\beta$-TCP) que não reagiram. Além disso, observa-se que os métodos avaliados não alteram a reação de cura do cimento e nem a composição e a morfologia do material final.

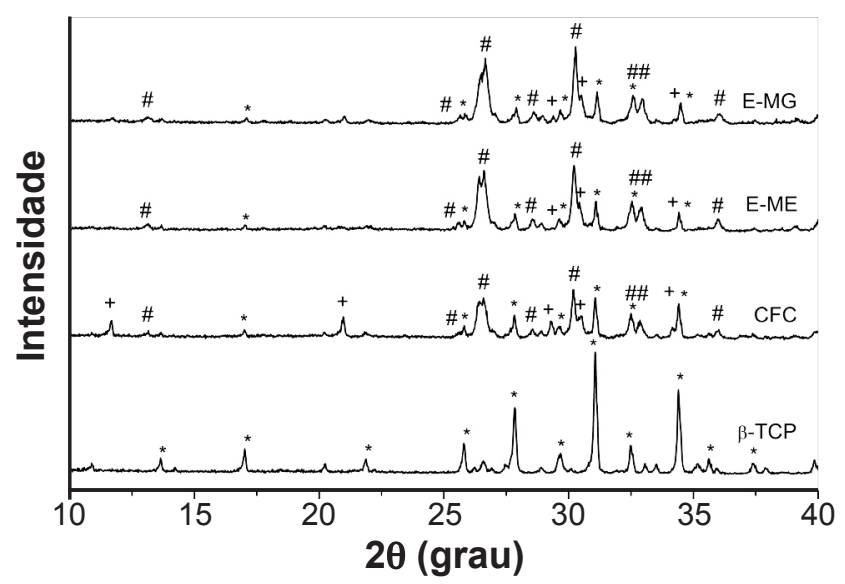

Figura 1: Difratogramas de raios $\mathrm{X}$ das espumas, do $\mathrm{CFC}$ e do $\beta$-TCP. CFC: cimento de $\beta$-TCP; E-ME: espumas obtidas por emulsão; E-MG: espumas obtidas por gelcasting. Legenda: * $\beta$-TCP, \# DCPA, + DCPD.

[Figure 1: XRD patterns of the foams, CPC and $\beta$-TCP. CPC: $\beta$-TCP cement; $E-M E$ : foams obtained by emulsion; $E-M G$ : foams obtained by gelcasting. Legend: * $\beta-T C P$, \# DCPA, + DCPD.]

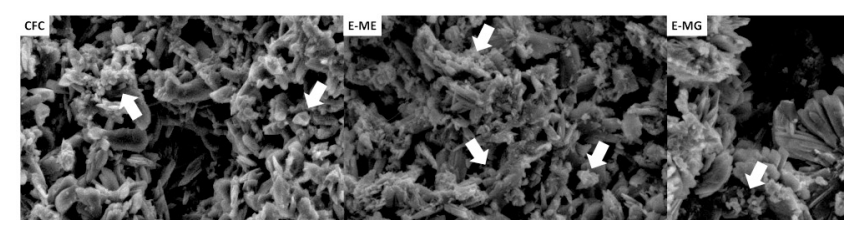

Figura 2: Morfologia do cimento e das espumas obtidas neste estudo. Setas brancas indicam partículas de $\beta$-TCP sem reagir.

[Figure 2: Morphology of the cement and foams obtained in this study. White arrows indicate $\beta$-TCP particles without reacting.]

Ambos os métodos foram eficientes em fabricar espumas com porosidade variando entre 58,3-62,5\% (Tabela II). Quando comparados com o cimento de fosfato de cálcio, observa-se um aumento de $9 \%$ e $15 \%$ na porosidade das amostras preparadas pelo método de emulsão e gelcasting, respectivamente. Após análise ANOVA dos resultados obtidos, pode-se afirmar com $95 \%$ de certeza que o método de gelcasting é o que garante maior porosidade às amostras uma vez que o valor $p$ encontrado foi igual a zero. Os valores de porosidade para as espumas de CFC são similares ao da literatura $[14,15]$. Almirall e colaboradores encontraram valores de porosidade de $51-66 \%$ para espumas de cimento de $\alpha$-TCP, quando utilizaram o $\mathrm{H}_{2} \mathrm{O}_{2}$ como agente formador de poros [14].

A porosidade das espumas e do cimento de $\beta$-TCP

Tabela II - Porosidade aparente das amostras. As amostras são estatisticamente diferentes. (ANOVA, $\mathrm{p}=0$ )

[Table II - Apparent porosity of the samples. The samples are statistically different. (ANOVA, $p=0$ ).]

\begin{tabular}{ccc}
\hline \multicolumn{3}{c}{ Porosidade aparente (\%) } \\
\hline CFC & E-ME & E-MG \\
$53,4 \pm 0,8$ & $58,3 \pm 0,9$ & $62,5 \pm 1,9$ \\
\hline
\end{tabular}

bem como a sua morfologia podem ser observadas na Fig. 3. Para as espumas produzidas pelo método de emulsão nota-se uma distribuição homogênea de poros, os quais apresentam uma geometria que tende à esférica e tamanho médio de $100 \mu \mathrm{m}$ (Figs. 3-b-1 a b-3). Enquanto que pelo método de gelcasting, observa-se também uma distribuição homogênea de poros, porém os poros apresentam um formato irregular e tamanho médio de $50 \mu \mathrm{m}$ (Figs. 3-c-1 a c-3). Também foi verificado que diferentemente do observado para as espumas obtidas pelo método de gelcasting, os poros formados pelo método da emulsão são isolados. Além disso, observa-se em todas as amostras uma microporosidade $(\sim 5 \mu \mathrm{m})$, a qual está distribuída homogeneamente por toda a amostra e também nas paredes dos macroporos. É importante observar que esta microporosidade é um fator determinante na adsorção de proteínas e nos processos de reabsorção do material in vivo [16].

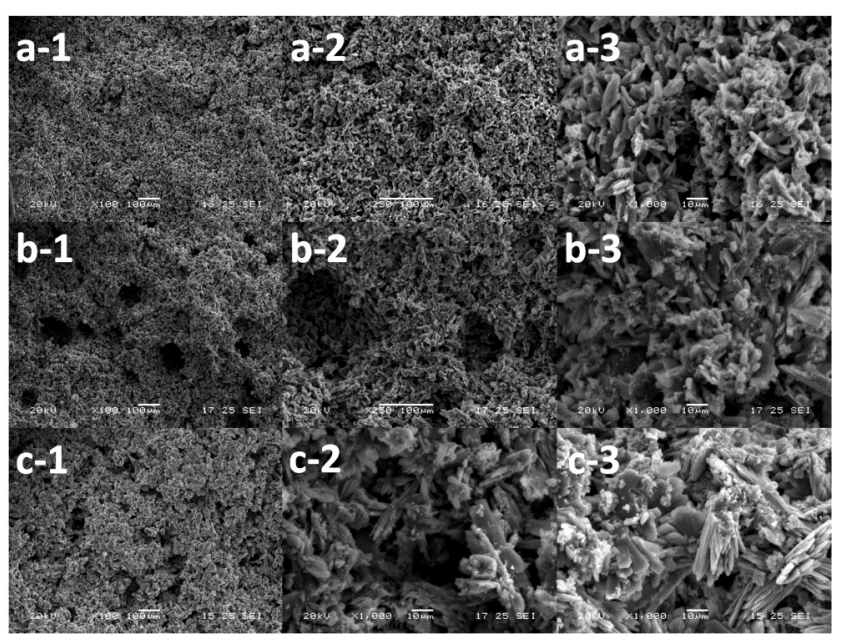

Figura 3: Micrografias de superfície de fratura das amostras: a) CFC; b) E-ME e c) E-MG.

[Figure 3: Surface of fracture's micrographs: a) CPC; b) $E-M E e$ c) $M-M G$.

Como esperado, o aumento na porosidade das amostras refletiu na resistência mecânica das espumas, conforme mostra a Fig. 4. Observa-se uma queda de $35 \%$ e $75 \%$ na resistência mecânica quando a porosidade apresenta um incremento de 9\% (E-ME) e 15\% (E-MG), respectivamente. 


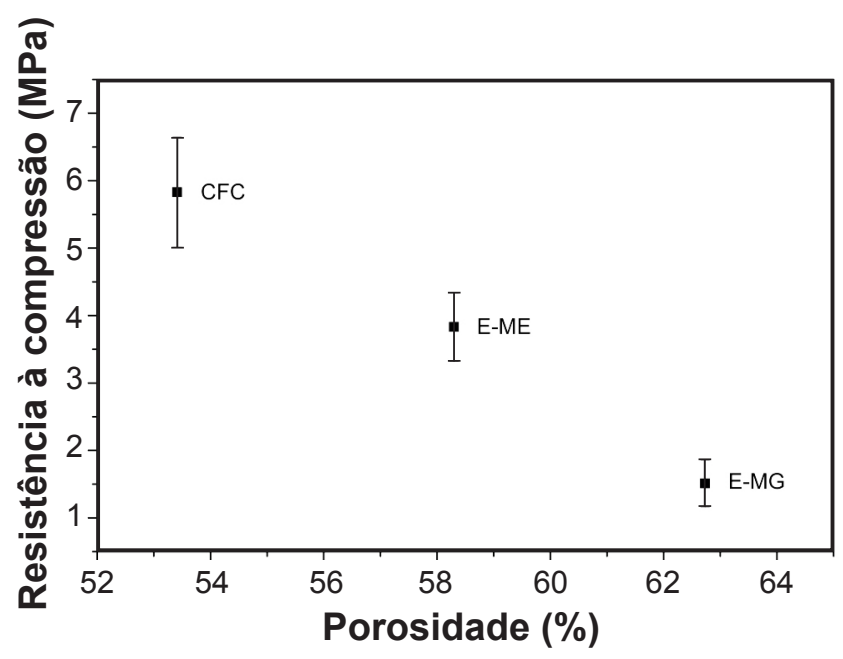

Figura 4: Resistência à compressão das espumas de cimento de fosfato de cálcio em função da porosidade.

[Figure 4: Mechanical strength of the calcium phosphate cement foams as a function of porosity.]

De fato, após teste estatístico ANOVA, é possível afirmar com $95 \%$ de confiabilidade $(p=0,000)$ que as amostras são estatisticamente diferentes. Uma vez que estes materiais são fabricados para serem utilizados como substitutos ósseos, é importante levar em consideração a resistência à compressão do osso humano: cortical (100 e $230 \mathrm{MPa})$ e esponjoso (2 e $12 \mathrm{MPa}$ ) [17]. Portanto, a aplicação da ECFC fica restrita à situações nas quais elevadas cargas não são solicitadas. É importante ressaltar que para aplicações em Engenharia Tecidual, a espuma cerâmica (scaffold) deve ser capaz de manter sua estrutura enquanto o processo biológico de remodelagem óssea ocorre.

\section{CONCLUSÕES}

Espumas de cimento à base de fosfato de cálcio foram obtidas com sucesso por meio das rotas de processamento propostas, emulsão e gelcasting. A porosidade das espumas variou numa faixa de $53-62 \%$ e a resistência mecânica variou entre 3,83-1,51 MPa. Apesar de se ter tido uma brusca redução na resistência mecânica das espumas, os valores obtidos ainda estão dentro da faixa referente ao osso esponjoso podendo ser aplicados na Engenharia Tecidual.

\section{AGRADECIMENTOS}

Os autores gostariam de agradecer ao LME/LNNano/ CNPEM pelo suporte técnico durante a realização das microscopias eletrônicas de varredura e ao Prof. Dr. Sergio Frascino Muller de Almeida pelo auxílio na realização dos ensaios mecânicos.

\section{REFERÊNCIAS}

[1] S. V. Dorozhkin, Materials 2 (2009) 221.

[2] M. P. Ginebra, M. Espanol, E. B. Montufar, R. A. Perez, G. Mestres, Acta Biomater. 6 (2010) 2863.

[3] M. Bohner, U. Gbureck, J. E. Barralet, Biomater. 26 (2005) 6423.

[4] H. R. Ramay, M. Zhang, Biomater. 24 (2003) 3293.

[5] L. Montanaro, Y. Jorand, G. Fantozzi, J. Negro, J. Eur. Ceram. Soc. 18 (1998) 1339.

[6] J. Saggio-Woyansky, C. E. Scott, W. P. Minnear, Am. Ceram. Soc. Bull. 71 (1992) 1674.

[7] P. Sepulveda, J. Am. Ceram. Soc. 76 (1997) 61.

[8] E. Sousa, M. Dellú Júnior, V. C. Pandolfelli, F. S. Ortega, Mater. Sci. Forum 498 (2008) 591.

[9] F. Leal-Calderon, V. Schmitt, J. Bibette, Emulsion science: basic principles, $2^{\text {nd }}$ Ed., Springer, New York, EUA (2007) 5.

[10] M. A. Janney, O. O. Omatete, "Method for moulding ceramic powders using water-based gel casting", US Patent 5028362, 1991.

[11] A. C. Young, O. O. Omatete, M. A. Janney, P. A. Menchhofer, J. Am. Ceram. Soc. 74 (1991) 612.

[12] M. P. Ginebra, T. Traykova, J. A. Planell, J. Contr. Rel. 113 (2006) 102.

[13] M. Bohner, H. P. Merkle, P. Van Landuyt, G. Trophardy, J. Lemaitre, J. Mater. Sci. Mater. Med. 11 (2000) 111.

[14] A. Almirall, G. Larrecq, J. A. Delgado, S. Martinez, J. A. Planell, M. P. Ginebra, Biomater. 25 (2004) 3671.

[15] S. G. Fullana, H. Ternet, M. Freche, J. L. Lacout, F. Rodriguez, Acta Biomater. 6 (2010) 2294.

[16] B. H. Fellah, P. Layrolle, Acta Biomaterialia, 5 (2009) 735.

[17] L. L. Hench, J. Wilson, An introduction to bioceramics, World Scientific, Singapore (1993) 12.

(Rec. 19/04/2011, Rev. 30/08/2011, Ac. 28/10/2011) 